\begin{tabular}{|l|l|l|}
\hline \multicolumn{2}{|c|}{ PublisherInfo } \\
\hline \hline PublisherName & $:$ & BioMed Central \\
\hline \hline PublisherLocation & $:$ & London \\
\hline \hline PublisherImprintName & $:$ & BioMed Central \\
\hline \hline
\end{tabular}

\title{
C-spine examination with dynamic fluoroscopy
}

\begin{tabular}{|l|l|l||}
\hline \multicolumn{2}{|c||}{ ArticleInfo } \\
\hline \hline ArticleID & $:$ & 4310 \\
\hline \hline ArticleDOI & $:$ & $10.1186 /$ ccf-2001-73306 \\
\hline \hline ArticleCitationID & $:$ & 73306 \\
\hline \hline ArticleSequenceNumber & $:$ & 21 \\
\hline \hline ArticleCategory & $:$ & Paper Report \\
\hline \hline ArticleFirstPage & $:$ & 1 \\
\hline \hline ArticleLastPage & $:$ & 3 \\
\hline \hline & & RegistrationDate : 2001-12-4 \\
ArticleHistory & $:$ & Received \\
\hline ArticleCopyright & $:$ 2001-8-2 \\
\hline \hline ArticleGrants & $:$ & OnlineDate \\
\hline \hline ArticleContext & $:$ & 1305455 \\
\hline \hline
\end{tabular}


Aff1 University of Aintree, LIverpool

\section{Keywords}

Fluoroscopy, head Injury, spinal injuries

\section{Context}

Classical trauma guidelines recommend cervical spine (C-spine) X-rays to rule out bone injury. However, injuries not involving bone, such as ligamentous or spinal cord injuries without radiological abnormality, can still occur with 'normal' C-spine X-rays. Therefore a hard collar should be fitted to the neck and the $\mathrm{C}$-spine immobilized until the patient regains consciousness and neck tenderness, which implies actual C-spine injury, can be assessed. However, many patients require prolonged ventilation and sedation in an ICU, which does not allow for such assessments to be carried out. Recommendations have ranged from removing the cervical collar to indefinite immobilization of the $\mathrm{C}$-spine. This study aims to evaluate the value of dynamic fluoroscopic examinations of the $\mathrm{C}$-spine in patients with head injury to determine the presence of ligamentous abnormalities.

\section{Significant findings}

Dynamic fluoroscopy of 301 trauma patients revealed 297 true negative, 2 true positive, 1 false positive and 1 false negative results. The true positives were treated and later discharged from the ICU. In the false positive patient, CT and MRI scans ruled out any ligament damage. In the false negative patient the initial C-spine $\mathrm{X}$-rays had been misinterpreted and dynamic fluoroscopy was carried out without visualising the entire $\mathrm{C}$-spine (i.e. $\mathrm{C} 0$-T1); the patient was rendered quadriplegic after removal of the cervical collar.

Due to its inherent risks, dynamic fluoroscopy must adhere to strict protocols. X-rays of the entire Cspine must be examined by a senior radiologist, who then directs the fluoroscopic examination assisted by ICU personnel. Unstable ligamentous C-spine injury is rare in the absence of vertebral fracture and in this study there was an incidence of $0.7 \%$. The $\mathrm{C}$-spine may be considered clear after adequate plain $\mathrm{X}$ rays supplemented with $\mathrm{CT}$ scan if required. 


\section{Comments}

This article addresses a practical issue in the ICU management of patients with head injuries who either have an altered mental status or require prolonged ventilatory support in the ICU. Although the incidence of ligamentous $\mathrm{C}$-spine injury is rare, quadriplegia resulting due to carelessness is catastrophic. The guidelines issued in 1998 in the Journal of Trauma from the Eastern Association for the Surgery of Trauma (EAST), a well respected body of opinion in the management of trauma, have been reinforced by this work with the addition of a dynamic, real-time technique of examining the $\mathrm{C}$ spine in trauma.

\section{Methods}

301 patients with closed heady injury, dynamic fluoroscopic examination of cervical spine.

\section{Additional information}

\section{References}

1. Davis JW, Kaups KL, Cunningham MA, Parks SN, Nowak TP, Bilello JF, Williams JL: Routine evaluation of the cervical cpine in head-injured patients with dynamic fluoroscopy: a reappraisal. $\mathrm{J}$ Trauma. 2001, 50: 1044-1047. 